\title{
ANÁLISE MICROBIOLÓGICA DE CALDOS DE CANA COMERCIALIZADOS EM CURITIBA, PARANÁ
}

\author{
(Microbiological analysis of sugarcane juice sold in Curitiba, Paraná)
}

Lew Kan Sprenger ${ }^{1}$, Larissa Wünsche Risolia, Sharif Zardo Hamdar, Marcelo Beltrão Molento

${ }^{1}$ Correspondência: lew.sprenger@gmail.com

RESUMO: O objetivo do estudo foi determinar as condições higiênico-sanitárias de caldos de cana comercializados em Curitiba, Paraná. Nos meses de setembro e outubro de 2014, foram coletadas e pesquisadas amostras provenientes de 49 pontos de venda, distribuídos em 21 bairros da cidade. Foram realizadas a contagem de bolores e leveduras, mesófilos aeróbicos, coliformes totais e fecais, Escherichia coli e Salmonella sp. Também foi realizada a análise de perigos físicos. O índice de contaminação com bolores e leveduras variou de 0,56 a 5,63 Log.UFC. $\mathrm{mL}^{-1}$ e para mesófilos aeróbicos oscilou entre 0,65 a 6,54 Log.UFC. $\mathrm{mL}^{-1}$. A presença de coliformes totais acima do limite estabelecido pela normativa vigente, 2 Log.UFC. $\mathrm{mL}^{-1}$, foi detectada em $34,04 \%(16 / 47)$ e para coliformes fecais este índice foi 10,64\% (5/47). Apenas 4,26\% (2/47) das amostras estavam contaminadas com E. coli, ao passo que não foi detectada (0/47) a presença de Salmonella sp. foi encontra a presença de fibras sintéticas em caldos de canas comercializados por $4,26 \%$ (2/47) dos pontos de venda. Os resultados observados no presente estudo apontam para a ocorrência de déficits higiênico-sanitários no processo de produção do caldo de cana comercializado na cidade de Curitiba-PR. A constatação de diversas amostras contaminadas colocam em risco a saúde do consumidor, pois o produto pode ser uma fonte de patógenos causadores de DTAs.

Palavras-chave: ambulantes; garapa; microbiologia de alimentos

ABSTRACT: The aim of this study was to determine the hygienic and sanitary conditions sugarcane juice sold in Curitiba, Paraná. In September and October 2014 were collected and surveyed samples from 49 street stands in 21 Curitiba's districts. Count of yeasts and molds, aerobic mesophilic, total and fecal coliforms, Escherichia coli and Salmonella spp. were performed. Analysis of physical hazards was also performed. The rate of contamination with molds and yeasts ranged from 0.56 to 5.63 Log.UFC. $\mathrm{mL}^{-1}$ and mesophilic aerobic ranged from 0.65 to 6.54 Log.UFC. $\mathrm{mL}^{-1}$. The presence of total coliforms above the limit established by the current legislation was detected in $34.04 \%(16 / 47)$ and to fecal coliform this index was $10.64 \%(5 / 47)$. Only $2.13 \%(1 / 47)$ of the samples were contaminated with $E$. coli and it was not detected $(0 / 47)$ the presence of Salmonella spp. The presence of synthetic fibers was observed in $4.26 \%(2 / 47)$ of the samples. The results observed in this study indicate the occurrence of hygienic failures in the production of sugarcane juice sold in Curitiba-PR. These contaminated samples are a danger to consumer health, because the product can be a source of foodborne pathogens.

Key Words: food microbiology; garapa; street vendors 


\section{INTRODUÇÃO}

Devido as mudanças impostas no conturbado estilo de vida industrial ocidental, é crescente a quantidade de pessoas que se alimentam fora dos domicílios. Este consumo é realizado tanto em estabelecimentos fixos ou móveis, os quais são distribuídos nas ruas pelos vendedores ambulantes. Esse comercio ganhou uma importância muito grande na atualidade, sendo que nas grandes cidades brasileiras, os habitantes gastam entre $25,74 \%$ da renda familiar nestes estabelecimentos alimentícios (Leal, 2010).

Entre as vantagens encontradas pelos consumidores destas comidas estão a praticidade, economia e agilidade. Apesar de demonstrar as referidas vantagens positivas, o principal ponto negativo existente está relacionado a qualidade higiênicosanitário (Genta et al., 2008). Assim sendo, demonstra-se a necessidade de estudos epidemiológicos acerca dos alimentos produzidos por terceiros, especialmente os fabricados em ruas, pois estes, normalmente, possuem condições higiênicas de fabricação mais precárias (Bezerra et al., 2010).

O caldo de cana, também conhecido como garapa, é uma bebida muito consumida em países tropicais, incluindo o Brasil, principalmente devido ao sabor doce e aroma agradável (Duarte et al., 2011). Este produto é vendido principalmente por vendedores ambulantes, que os produzem pela moagem da cana de açúcar moendas e subsequentemente coagem em peneiras de aço inox ou plástico. A cana pode possuir sujidades e microrganismos em seus colmos e folhas (Norberg et al., 2012). Todavia, é durante a fase de extração que ocorre os maiores casos de contaminação, devido à falta de higiene dos equipamentos, contaminação ambiental ou humana e condições inadequadas de manipulação (Nascimento et al., 2006). Além disso, o caldo de cana possui diversos nutrientes e condições propícias para o desenvolvimento de diversos patógenos (França, 2005). Nesta fase de produção, também há o risco de contaminação física com sujidades ou até mesmo partes de insetos (Norberg et al., 2012).

Sabendo da importância do controle higiênico-sanitário envolvido na obtenção da qualidade do produto, o presente estudo teve como objetivo avaliar a qualidade dos caldos de cana produzidos na cidade de Curitiba.

\section{MATERIAL E MÉTODOS}

No mês de outubro de 2014, foram coletadas 141 amostras de caldo 
Microbiological analysis of sugarcane juice sold in Curitiba, Paraná de cana, provenientes de 47
estabelecimentos ambulantes
localizados em 21 bairros de Curitiba,
Paraná. Após as coletas, as amostras
foram acondicionadas em frascos estéreis e identificadas, sendo em seguidas transferidas para caixas isotérmicas contendo gelo e encaminhadas ao Laboratório de Microbiologia de Alimentos da Universidade do Contestado, Campus Marcílio Dias.

$\mathrm{Na}$ análise microbiológica, para a enumeração de bolores e leveduras utilizou-se a semeadura em Ágar Batata Dextrose, com incubação de $25^{\circ} \mathrm{C}$ por 5dias. Na quantificação de bactérias mesófilas aeróbias totais foi utilizada a semeadura em Ágar Para Contagem Total (Plate Count Agar - PCA), com incubação por 24 horas a $37^{\circ} \mathrm{C}$. Para a determinação de coliformes totais e fecais foi empregada a técnica do Número Mais Provável (NMP). Na análise de coliformes totais foram usados o Caldo Lauril Sulfato de Sódio (LST), com incubação de 48 horas a $35^{\circ} \mathrm{C}$. A partir do teste presuntivo, usouse para o teste confirmatório o Caldo Lactosado Bile Verde Brilhante, com incubação por 24 a 48 horas a $35^{\circ} \mathrm{C}$. A contagem de coliformes fecais foi feita em Caldo Escherichia coli com incubação por 24 horas a $45^{\circ} \mathrm{C}$. Para pesquisa de E.coli os tubos de caldo LST positivos, foram transferidos para tubos de caldo triptona $1 \%$ e incubados por 24 horas a $35^{\circ} \mathrm{C}$, sendo que para a confirmação utilizou-se 0 reagente Kovacs. Para pesquisa de Salmonella sp. procedeu-se o pré enriquecimento com água peptonada tamponada e incubação por 24 horas a $36^{\circ} \mathrm{C}$, com sequente enriquecimento com caldo Rappaport-Vassiliades e selenito cistina, sendo o primeiro incubado a $35^{\circ} \mathrm{C}$ e $\mathrm{O}$ segundo a $42^{\circ} \mathrm{C}$ por 24 horas. Transcorrido o referido processo, foi realizado o plaqueamento em Agar verde brilhante-BG e Agar xilose lisina desoxicolato - XLD e incubação por 24 horas a $36^{\circ} \mathrm{C}$. Por fim, transferido $\mathrm{O}$ período de incubação do plaqueamento, realizou-se a triagem das colônias utilizando o meio TSI e LIA.

A análise física do caldo de cana, procedeu-se através do método descrito pela Association of Official Analytical Chemists (AOAC) modificado. Foram usados $250 \mathrm{~mL}$ da amostra, com duas extrações subsequentes com óleo mineral em frasco armadilha de Wildman. Após, retirou-se a camada oleosa e o material foi examinado ao microscópio estereoscópico.

Os dados colhidos durante o período experimental foram analisados utilizando o programa Epi Info® versão 
3.5.1. Os resultados das análises microbiológicas foram transformados em logaritmos (Log.UFC. $\mathrm{mL}^{-1}$ ) comparados com os padrões estabelecidos na RDC № 12, de 02 de janeiro de 2001 (Brasil, 2001).

\section{RESULTADOS E DISCUSSÃO}

Os resultados obtidos das análises microbiológicas estão dispostos na Tabela 1. A contagem de bolores e leveduras variou entre 0,56 a 5,63 Log.UFC. $\mathrm{mL}^{-1}$. Em estudo realizado na cidade de Umuarama-PR, a carga microbiana quantificada ficou na ordem de 4,91 a 6,04 Log.UFC. $\mathrm{mL}^{-1}$ (Gandra et al., 2007). A contagem de bolores e leveduras, era exigida pela Portaria $n^{\circ}$ 451 de 19 de setembro de 1997 do Ministério da Saúde (Brasil, 1997). Todavia esta foi revogada pela atual Portaria, RDC no 12, de 02 de janeiro de 2001 (Brasil, 2001), a qual não exige a contagem destes patógenos. Bolores e leveduras são contaminantes comumente encontrados em sucos e extratos de frutas e vegetais, especialmente quando $o$ alimento entra em contato com o solo, como é o caso da cana de açúcar (Norberg et al., 2012). Estes patógenos são importantes do ponto de vista sanitário, pois possuem capacidade de deteriorar os substratos nos quais se encontram, além de muitos produzirem micotoxinas (Lopes et al., 2007).

\begin{tabular}{|c|c|c|c|c|c|c|}
\hline Amostra & \begin{tabular}{|l|} 
Bolores a \\
Leveduras \\
\end{tabular} & $\begin{array}{l}\text { Mesófilas } \\
\text { Aeróbias } \\
\end{array}$ & $\begin{array}{c}\text { Coliformes } \\
\text { Totais }\end{array}$ & $\begin{array}{c}\text { Coliformes } \\
\text { Fecais }\end{array}$ & $\begin{array}{c}\text { Eschenichio } \\
\text { sell }\end{array}$ & Salmonellasp. \\
\hline 1 & 0,81 & 1,24 & 0,74 & 0,74 & Ausente & Ausente \\
\hline 2 & 2,32 & 6,54 & 1,87 & 0,53 & Ausente & Ausente \\
\hline 3 & 3.22 & 5,12 & 2,98 & 2,04 & Presente & Ausente \\
\hline 4 & 0.86 & 2,88 & 1.04 & 1.04 & Ausente & Ausente \\
\hline 5 & 0,56 & 1,96 & 0.68 & 0.57 & Ausente & Ausente \\
\hline$\theta$ & 4,24 & 2,87 & 1.95 & 1,95 & Ausente & Ausente \\
\hline 7 & 5,63 & 4.88 & 2,84 & 2,34 & Ausente & Ausente \\
\hline 8 & 5,02 & 3,78 & 3,06 & 2,18 & Presente & Ausente \\
\hline 9 & 0.88 & 0,85 & 0.46 & 0.24 & Ausente & Ausente \\
\hline 10 & 0,88 & 1,03 & 0,78 & 0,76 & Ausente & Ausente \\
\hline 11 & 1,12 & 3,08 & 2,54 & 1.84 & Ausente & Ausente \\
\hline 12 & 2,01 & 3,75 & 1.85 & 1,37 & Ausente & Ausente \\
\hline 13 & 3.42 & 4,88 & 2,04 & 1.96 & Ausente & Ausente \\
\hline 14 & 0,86 & 3,87 & 1.48 & 0,43 & Ausente & Ausente \\
\hline 15 & 1.17 & 1,85 & 1,64 & 1.05 & Ausente & Ausente \\
\hline 16 & 2,43 & 2,37 & 2,65 & 2,17 & Ausente & Ausente \\
\hline 17 & 3,07 & 2,89 & 2,34 & 1.53 & Ausente & Ausente \\
\hline 18 & 2,88 & 1,07 & 1,59 & 1,03 & Ausente & Ausente \\
\hline 10 & 3,12 & 4,08 & 2,87 & 0.64 & Ausente & Ausente \\
\hline 20 & 1,34 & 3,12 & 1,69 & 1.84 & Ausente & Ausente \\
\hline 21 & 4.98 & 5,64 & 2.86 & 0,56 & Ausente & Ausente \\
\hline 22 & 1.88 & 0,89 & 0,74 & 0.38 & Ausente & Ausente \\
\hline 23 & 5,02 & 4.85 & 3,07 & 2,34 & Ausente & Ausente \\
\hline 24 & 1,56 & 2.46 & 1.84 & 1.16 & Ausente & Ausente \\
\hline 25 & 1.42 & 3,05 & 1.27 & 0,03 & Ausente & Ausente \\
\hline 28 & 1.88 & 1,56 & 1,75 & 1,75 & Ausente & Ausente \\
\hline 27 & 1.78 & 2,06 & 1.71 & 1.71 & Ausente & Ausente \\
\hline 28 & 1,65 & 1,98 & 1,68 & 1.05 & Ausente & Ausente \\
\hline 28 & 0.87 & 2.07 & 0,68 & 0.28 & Ausente & Ausente \\
\hline 30 & 1,82 & 2,85 & 1,07 & 1.07 & Ausente & Ausente \\
\hline 31 & 1,85 & 1,43 & 1,03 & 0.28 & Ausente & Ausente \\
\hline 32 & 1.98 & 2.48 & 1,52 & 1.05 & Ausente & Ausente \\
\hline 33 & 2,34 & 3,00 & 2.08 & 1,34 & Ausente & Ausente \\
\hline 34 & 3,08 & 1,85 & 1,67 & 1.71 & Ausente & Ausente \\
\hline 35 & 2.86 & 0.69 & 0.85 & 0.95 & Ausente & Ausente \\
\hline 36 & 3.06 & 1,85 & 1,48 & 1.07 & Ausente & Ausente \\
\hline 37 & 4.48 & 1,85 & 2,94 & 1.28 & Ausente & Ausente \\
\hline 38 & 2,00 & 1,67 & 2,07 & 1.65 & Ausente & Ausente \\
\hline 38 & 1,33 & 0,84 & 1.11 & 1.11 & Ausente & Ausente \\
\hline 40 & 1,85 & 1,36 & 2,04 & 1,25 & Ausente & Ausente \\
\hline 41 & 1.33 & 2.34 & 1,52 & 1.58 & Ausente & Ausente \\
\hline 42 & 3.88 & 2,84 & 2,17 & 1.47 & Ausente & Ausente \\
\hline 43 & 2.84 & 2,05 & 1.86 & 1.46 & Ausente & Ausente \\
\hline 44 & 3.43 & $2.4 \theta$ & 2,52 & 0,84 & Ausente & Ausente \\
\hline 45 & 1,84 & 0,69 & 0.98 & 0.88 & Ausente & Ausente \\
\hline 46 & 1.55 & 1.47 & 1.11 & 0,69 & Ausente & Ausente \\
\hline 47 & 1,82 & 2,74 & 1,42 & 0,78 & Ausente & Ausente \\
\hline
\end{tabular}

A quantificação de bactérias mesófilas aeróbias variou entre 0,65 a 6,54 Log.UFC. $\mathrm{mL}^{-1}$ (Tabela 1). Este é outro microrganismo que não possui padrões estabelecidos na atual legislação nacional para caldo de cana. Todavia, sua pesquisa é muito utilizada na indústria alimentícia, pois há uma grande correlação negativa entre a sua presença e qualidade higiênica dos alimentos (Fortuna et al., 2013). A presença em elevada quantidade de 
microrganismos mesófilos aeróbicos, torna o alimento insalubre (Coelho et al, 2010). Quando a contagem desta bactérias é igual ou superior a 6 Log.UFC. $\mathrm{mL}^{-1}$, a qualidade do produto pode apresentar alterações sensoriais ou organolépticas significativas, podendo apresentar deterioração visível (Prati et al., 2004).

A principal fonte de contaminação com patógenos mesófilos aeróbicos é o gelo, o qual deve ser fabricado a base de água potável e ser mantido em condição higiênico-sanitária que evite sua contaminação (Ferreira et al., 2014). A contaminação do gelo ocorreu provavelmente pelas condições de infraestrutura dos pontos de venda dos caldo de cana, pela fonte contaminada de água que originou o produto e pelo manuseio inadequado do produto, com o contato direto do gelo com as mãos dos funcionários, que o manipulavam sem uniformes e sem luvas.

$\mathrm{Na}$ análise de coliformes totais $34,04 \%$ (16/47) obtiveram contagens superiores a 2 Log.UFC. $\mathrm{mL}^{-1}$ (Tabela 1), limite $o$ qual é estabelecido pela normativa vigente (Brasil, 2001). Este número é inferior ao encontrados em outras pesquisas já realizadas, onde em Vitória-ES (Kitoko et al., 2004) e BelémPA (Soares, 1999) observou-se 100\% de positividade. A contagem de coliformes fecais, também chamados de coliformes termotolerantes, indicou positividade, amostras com número de bactérias superior a 2 Log.UFC. $\mathrm{mL}^{-1}$, em 10,64\% (5/47) (Tabela 1). Este valor é inferir ao encontrado em outros trabalhos realizados, como em Umuarama-PR, onde foi verificada $58,33 \%$ de contaminação (Gandra et al., 2007) e também em Itumbiara-GO onde constatou-se $20 \%$ de amostras fora dos padrões (Felipe \& Miguel, 2012). Todavia é superior ao índice encontrado por Lopes et al. (2007), que observou a presença de coliformes fecais em apenas $3,33 \%$ das amostras analisadas provenientes de Curitiba-PR.

Mesmo não sendo obrigatório é importante diferenciar E. coli dos outros coliformes termotolerantes, pois 0 primeiro é o único com origem exclusivamente fecal. Esta bactéria possui elevado potencial patogênico, pois produz toxina e/ou as células entéricas causando grandes agravos a saúde dos homens e animais (Bezerra, 2008). Foi encontrada E. coli em $4,26 \%$ (2/47) das amostras testadas (Tabela 1). Felipe \& Miguel (2012) observaram que $20 \%$ das amostras analisadas apresentaram presença da referida enterobactéria (Cunha, 2009). 
As taxas de contaminação encontradas no presente estudo são preocupantes, pois os coliformes, especialmente os coliformes fecais, são patógenos que possuem grande impacto na saúde humana, causando casos moderados a graves de problemas gastrointestinais (Kaminski \& Barreto, 2013). A presença destes microrganismos em alimentos ocorre principalmente por falhas higiênicas acentuadas, devido a contaminação humana e/ou dos utensílios utilizados na produção (Júnior et al., 2013).

Quanto a presença de Salmonella spp., a lei atual estabelece que os produtos devem ser ausentes deste patógeno. Nas amostras pesquisadas não foi encontrada em nenhuma bactéria 0\% (0/47) (Tabela 1). Nos Estados Unidos, estima-se que são gastos de um bilhão de dólares anualmente para tratar pacientes infectados com esta bactéria (Yamaguchi et al., 2013). No Brasil, ocorre subnotificações de casos de salmonelose, contudo sabe-se que esta é a mais perigosa doença transmitida por alimentos (DTAs), devido aos casos agudos da enfermidade, os quais podem ser fatais (Santos et al., 2011).

Quanto as análises de perigos físicos, em 4,26\% (2/47) foram encontradas fibras sintéticas. Prado et al. (2010) analisando amostras provenientes de Ribeirão Preto-SP, encontraram além de fibras sintéticas, pelos de roedores, fragmentos de insetos, ácaros, fibras metálicas, areia e terra. Segundo a Portaria, RDC № 218, de 02 de janeiro de 2005 substâncias ou agentes de origem física, estranhos às bebidas considerados nocivos à saúde humana ou que comprometam a sua integridade são considerados contaminantes (Brasil, 2005).

Os resultados encontrados no presente estudo decorrem de diversas falhas ocorridas, desde a colheita da cana de açúcar até a produção e armazenamento do caldo de cana. Entre estas quebras de protocolo higiênicas estão: uso de matéria prima com sujidades, utilização de fontes de água desconhecidas, falta de asseio pessoal e hábitos higiênicos precários dos produtores, manipulação de dinheiro sem posterior higienização das mãos, falta de higienização dos utensílios usados em todo o processo produtivo, acondicionamento inadequado do produto, matéria prima e produto exposto a grandes variações de temperatura e falta de proteção dos locais de venda contra perigos físicos e biológicos.

O problema de contaminação em caldos de cana já tinha sido observado 
anteriormente na cidade de Curitiba (Soccol et al., 1990; Lopes et al., 2006), entretanto este é um problema que atinge diversas outras localidades do país (Kikoto et al., 2004; Gandra et al., 2007; Prado et al., 2010; Norberg et al., 2012). Para evitar futuros problemas, os produtores devem implantar em toda a cadeia produtiva as boas práticas de fabricação (BPF), visando minimizar os perigos para níveis aceitáveis ou até mesmo eliminá-los. São práticas simples, baratas e de fácil implantação, sendo rapidamente assimiladas por produtores, independente de nível de escolaridade (Genta et al., 2008).

\section{CONCLUSÃO}

Os resultados observados no presente estudo apontam para a ocorrência de déficits higiênicosanitários no processo de produção do caldo de cana comercializado na cidade de Curitiba-PR. A constatação de diversas amostras contaminadas colocam em risco a saúde do consumidor, pois o caldo de cana serve como uma fonte de patógenos causadores de DTAs. A secretária municipal de saúde deve realizar cursos de treinamento e atualização em práticas higiênico-sanitárias para os ambulantes, visando diminuir estes índices alarmantes.

\section{REFERÊNCIAS}

ASSOCIATION OF OFFICIAL ANALYTICAL CHEMISTS (AOAC). Official Methods of Analysis of AOAC International, 18th ed., Gaithersburg, 2005. cap. 16. CD-Rom.

BEZERRA, A. C. D.; REIS, R. B. D.; BASTOS, D. H. M. et al. Microbiological quality of hamburgers sold in the streets of Cuiabá-MT, Brazil and vendor hygiene-awareness. Food Science and Technology, v.30, n.2, p.520-524, 2010.

BRASIL. Ministério da Saúde. Agência Nacional de Vigilância Sanitária. Resolução - RDC n.ำ 12, de 2 de janeiro de 2001. Regulamento técnico sobre padrões microbiológicos para alimentos. Diário Oficial [da] União, Brasília, 10 jan. 2001, Seção 1, p. 45-53. Disponível em: <http://www.anvisa.gov.br>. Acesso em: 20 out. 2014

BRASIL. Portaria $n^{\circ} 451$, de 19 de setembro de 1997. Regulamento técnico. Princípios gerais para 0 abastecimento de critérios e padrões microbiológicos para alimentos. Diário Oficial da República Federativa do Brasil, Brasil, n 182, p. 21005-21011, 22 set. 1997, seção I.

BRASIL. Agência Nacional de Vigilância Sanitária [ANVISA] do Ministério da Saúde. Resolução - RDC n²18, de 29 de julho de 2005. Dispõe sobre o regulamento técnico de procedimentos higiênico-sanitários para manipulação de alimentos e bebidas preparados com vegetais. Diário Oficial [da] República Federativa do Brasil, Poder Executivo, Brasília, DF, 1 ago. 2005. Seção 1.

COELHO, M. I. S.; MENDES, E. S.; CRUZ, M. C. S. et al. Avaliação da qualidade microbiológica de águas minerais consumidas na região metropolitana de Recife, Estado de Pernambuco. Acta Science Health Science, v.32, n.1, p.1-8, 2010. 
DUARTE, D. L.; VIEIRA, D. A. D. P.; MACHADO. et al. CALDO DE CANA CONSUMIDO EM VIAS PÚBLICASUMA REVISÃO. Cadernos de Educação, Tecnologia Sociedade, v.2, n.1, p.1-4, 2011.

FERREIRA, E. M.; LOPES, I. S.; PEREIRA, D. M. et al. Qualidade microbiológica do peixe serra (Scomberomerus brasiliensis) e do gelo utilizado na sua conservação. Arquivo do Instituto biológico, v.81, n.1, p.4954, 2014.

FRANÇA, A.F.; Avaliação da Qualidade Microbiológica do Caldo de Cana Comercializado na Área de Abrangência do Distrito Sanitário 5. Recife: UFRPE 2005, 53p.

FORTUNA, J. L.; NASCIMENTO, E. R.; FRANCO, R. M. et al. Correlação entre contagem de bactérias heterotróficas aeróbias mesófilas $\mathrm{e}$ isolamento de Salmonella spp. em hambúrgueres crus. Revista Brasileira de Ciência Veterinária, v.20, n.1, p.59-63, 2013.

GANDRA, E. A.; REITEMBACH, A. F.; BOLANHO, B. C. et al. Condições Microbiológicas de Caldos de Cana Comercializados em Umuarama (PR). Revista Brasileira de Tecnologia Agroindustrial, v.1, n.2, p.61-69, 2007.

GENTA, T. M. S.; MAURícIO, A. A.; MATIOLI, G. et al. Avaliação das Boas Práticas através de check-list aplicado em restaurantes self-service da região central de Maringá, Estado do Paraná. Acta Scientiarum. Health Science, v.27, n.2, p.151-156, 2008.

KITOKO, P. M.; OLIVEIRA, A C.; SILVA, M. L. et al. Avaliação microbiológica do caldo de cana comercializado em Vitória, Espírito Santo, Brasil. Higiene Alimentar, v.18, n.119, p.73-76, 2004.

LEAL, D. Crescimento da alimentação fora do domicílio. Segurança Alimentar e Nutricional, v.17, n.1, p.123-132, 2010
LOPES, G.; CRESTO, R.; CARRARO, $\mathrm{M}$. et al. Análise microbiológica de caldos de cana comercializadas na ruas de Curitiba, PR. Higiene alimentar, v.20, n.147, p.40-44, 2006.

NASCIMENTO, A.R.; MOUCHREK FILHO, V.E.; MOUCHREK FILHO, J.E.et al. Perfil microbiológico do caldo de cana comercializado na cidade de São Luís, MA. Higiene Alimentar, v.20, n.141, p.83-86, 2006.

NORBERG, A. N.; OLIVEIRA, J. T. M.; MONTEIRO, A. N. et al. Análise qualitativa e quantitativa de caldos de cana comercializados na região da Baixada Fluminense, estado do Rio de Janeiro, Brasil, quanto à poluição por Staphylococcus aureus. CIÊNCIA \& TECNOLOGIA, p.54-59, v.12, n. 2, 2012.

PRADO, S. D. P. T.; BERGAMINI, A. M. M.; RIBEIRO, E. G. A. et al. Avaliação do perfil microbiológico e microscópico do caldo de cana in natura comercializado por ambulantes. Revista do Instituto Adolfo Lutz, v.69, n.1, p.55-61, 2010.

PRATI, P. Desenvolvimento de processo de estabilização de caldo de cana adicionado de sucos de frutas ácidas. 2004. Campinas. Tese (Doutorado em Tecnologia de Alimentos) - Universidade Estadual de Campinas. 297p.

SOARES, M. S. Estudo comparativo de métodos de enumeração de coliformes em alimentos. 1999. Belém, 52p. Trabalho de Conclusão de Curso (Especialização em Tecnologia de Alimentos) - Universidade Federal do Pará.

SOCCOL, C. R.; SCHWAB, A.; KATAOKA, C. E. et al. Avaliação microbiológica do caldo de cana (garapa) na cidade de Curitiba. Boletim do Centro de Pesquisa de Processamento de Alimentos, v.8, n.2, p.116-125, 1990. 